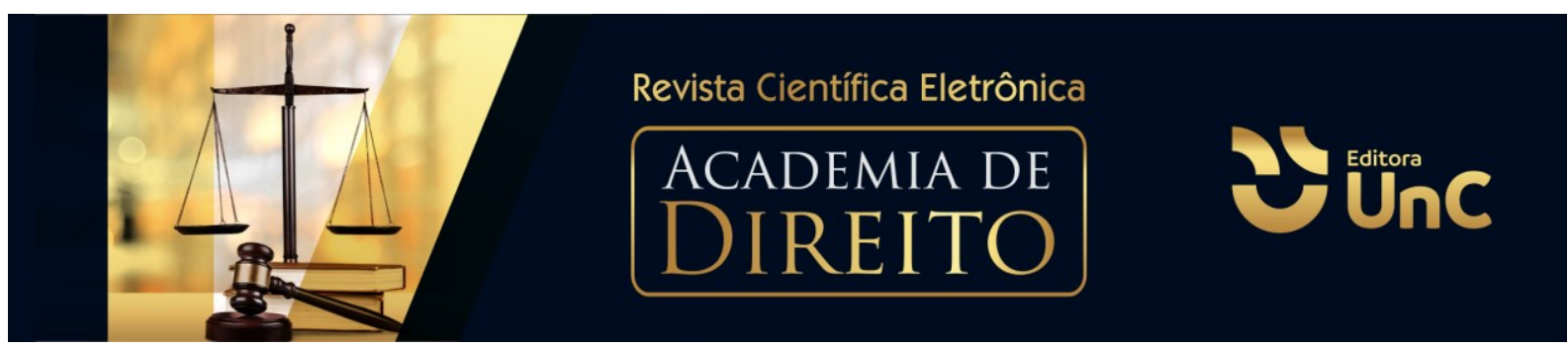

\title{
A PROVIDÊNCIA JURISDICIONAL E A PERCEPÇÃO DE AUXÍLIO-DOENÇA À MULHER VÍTIMA DE VIOLÊNCIA DOMÉSTICA
}

\section{JURISDICTIONAL PROVIDENCE AND THE PERCEPTION OF ILLNESS AID TO WOMEN VICTIMS OF DOMESTIC VIOLENCE}

\author{
Larissa da Silva de Assis ${ }^{1}$ \\ Alan Pinheiro de Paula ${ }^{2}$
}

\begin{abstract}
RESUMO
A seguridade social compreende a interação entre os Poderes Públicos e a sociedade e tem como um de seus objetivos o direito à previdência social. Elencada como instrumento da ordem social, é classificada como direito fundamental de segunda geração e, desta forma, imprescindível a atuação do Estado. O objetivo do presente trabalho foi demonstrar a necessidade de o Estado amparar vítimas de violência doméstica por meio do benefício previdenciário auxílio-doença. Mesmo com a promulgação da Lei 11.340/2006 (Lei Maria da Penha), a prestação estatal é indispensável para atender as necessidades dessa categoria vulnerável. Com isso, esta pesquisa tomou como base decisão proferida pelo Superior Tribunal de Justiça STJ, que determinou ao Instituto Nacional do Seguro Social o pagamento do citado benefício às vítimas de violência doméstica, cabendo a esta autarquia, por sua vez, buscar o ressarcimento do erário diante da indisponibilidade do interesse público. $O$ presente estudo deu-se pelo método indutivo e por meio de consultas bibliográficas, leitura de artigos, jurisprudência e interdisciplinaridade, a partir da apresentação e compreensão da providência jurisdicional à mulher vítima de violência doméstica.
\end{abstract}

Palavras-Chave: Previdência. Auxílio-doença. Violência. Jurisprudência. Mulher.

\begin{abstract}
The social security comprises the interaction between Public Authorities and society and one of its objectives is the right to social security. Listed as an instrument of social order, it is classified as a second generation fundamental right and, therefore, essential to the performance of the State. The objective of this study was to demonstrate the need for the State to support victims of domestic violence through the social security

\footnotetext{
${ }^{1}$ Graduanda em Direito, Universidade do Contestado. Campus Mafra. Santa Catarina. Brasil. E-mail: larissadeassis@outlook.com

${ }^{2}$ Mestre em Ciência Jurídica pela Universidade do Vale do Itajaí (UNIVALI). Delegado de Polícia. Professor de Direito na Universidade do Vale do Itajaí (UNIVALI) e na Universidade do Contestado (UNC). Campus Mafra. Santa Catarina. Brasil. E-mail: alanpinheirodepaula@gmail.com
} 
Sickness Benefit. Even with the promulgation of the Law 11.340/2006 (Maria da Penha Law), the state provision is essential to meet the needs of this vulnerable category. As a result, this research was based on a decision made by the Superior Court of Justice - STJ, which ordered the National Social Security Institute to pay the mentioned benefit to victims of domestic violence, and this autarchy, in turn, must seek the reimbursement of the treasury in view of unavailability of the public interest. The present study was carried out by the inductive method and through bibliographic consultations, reading of articles, jurisprudence, and interdisciplinary, based on the presentation and understanding of the judicial provision for women victims of domestic violence.

Keywords: Social Security. Sickness Benefit. Violence. Jurisprudence. Woman.

\section{INTRODUÇÃO}

A vigência da Lei 11.340/2006, batizada como Lei Maria da Penha, teve como objeto a proteção da mulher vítima de violência doméstica. Entretanto, os índices de agressões cometidas no seio familiar continuam alarmantes, sendo indispensáveis outros mecanismos de proteção e repressão.

Neste sentido, o presente estudo intitulado "a providência jurisdicional e a percepção de auxílio-doença à mulher vítima de violência doméstica", tem como objetivo demonstrar se é viável ao Estado amparar vítimas de violência doméstica por meio do reconhecimento de benefício previdenciário auxílio-doença.

Esta pesquisa tomou como base uma decisão proferida pelo Superior Tribunal de Justiça, que atribuiu ao Instituto Nacional do Seguro Social o dever de arcar com a subsistência destas vítimas mediante benefício citado acima. Logo, por ser tratar de um julgamento pronunciado por um tribunal superior, será feita uma análise desta decisão acerca da possibilidade de o Judiciário reconhecer o supramencionado benefício.

Na primeira seção, será contextualizado o patriarcado como modelo familiar, sua historicidade e implicações sociais. Na seção seguinte, será abordada a tutela do Poder Público em relação à vítima de violência doméstica, sob a perspectiva preventiva e repressiva. Na derradeira seção, será discutida a possibilidade da tutela jurisdicional acerca da concessão de benefício previdenciário como forma de proteção das vítimas de violência doméstica. 
Ante o exposto, esta pesquisa busca compreender e responder a questão citada acima, por meio de método indutivo, pesquisa bibliográfica, doutrinária e jurisprudencial.

\section{DESENVOLVIMENTO HISTÓRICO DAS ESFERAS: PATRIARCADO, DESIGUALDADE DE GÊNERO E VIOLÊNCIA DOMÉSTICA}

Inicialmente, para debater a respeito da providência jurisdicional e a percepção do benefício auxílio-doença às mulheres vítimas de violência doméstica, há necessidade de contextualizar alguns conceitos essenciais para a compreensão do que versa o assunto aqui discutido. De imediato, é imperioso salientar como o patriarcado tornou-se um modelo de sociedade no decorrer da história. Por conseguinte, entender a importância que os movimentos sociais, protagonizados pelas mulheres, tiveram para a descaracterização desta forma de corpo social. Necessário também delimitar a definição de "violência doméstica" e determinar as implicações desse conceito.

\subsection{O PATRIARCADO COMO MODELO DE SOCIEDADE}

Apesar de hoje existir uma discussão muito mais expressiva e consciente em relação à igualdade de gênero no mercado de trabalho, ainda assim, dentro das organizações familiares, educacionais e políticas, a dominação masculina é muito evidente. Uma Consequência de toda uma construção histórica em que teorias eram formadas para tentar justificar a submissão feminina.

Segundo conceito etimológico, patriarcado vem do grego e quer dizer: patér, "pai" e arkhé, "poder"3 - pai no poder - e, com isso, pode-se definir que uma sociedade patriarcal é aquela em que a representação masculina detém toda a autoridade familiar.

O patriarcado consiste basicamente na dominação definida pela sociologia de Max Weber. O autor Weber (2004, p. 188), determina que "dominação, no sentido

${ }^{3}$ Conceito conforme pesquisa feita em Dicionário Houaiss, versão eletrônica, verbete patriarcado. (N.T.) 
muito geral de poder, isto é, de possibilidade de impor ao comportamento de terceiros a vontade própria, pode apresentar-se nas formas mais diversas".

Sendo assim, o autor explica que a teoria utilizada para o patriarcado é a do poder de mando autoritário, ou seja, o dominador, por vontade, influência as ações dos que serão os dominados, e estes realizam com obediência a ordem dada (WEBER, 2004, p. 191).

Weber (2004, p. 234-325) considera o patriarcalismo como o poder familiar ante ao aspecto de posse. Assim, o que estiver no domínio doméstico de um homem é tratado como sua propriedade, a despeito da dignidade da mulher.

Desta forma, contextualizado o conceito de patriarcado, Maria Beatriz Nader (2002, p. 471-472) descreve o modelo familiar patriarcal como a subordinação da mulher ao pai, irmão, marido ou qualquer que seja a figura masculina, pois esta era considerada uma mão-de-obra barata ao serviço doméstico. $E$ devido à escassez e desvalorização desse tipo de trabalho, passou-se a enxergar como "função" exclusiva da mulher.

Neste cenário, começa-se a mistificação da subordinação feminina à masculina, e com isso a aceitação de diversas imposições e obrigações que eram reputados como uma sociedade natural. À vista disso, Nader (2002, p. 475) explica que essa superioridade masculina de dominação de quem quer que seja divide a população e cria uma desigualdade social entre as classes.

Igualmente, Heleieth Saffiot (2005, p. 42-43) descreve o patriarcado "não apenas uma hierarquia entre as categorias de sexo; traz em seu bojo uma contradição de interesses". Ou seja, o patriarcado é muito mais que apenas um modelo prejudicial de sociedade.

A partir dessa relação hierárquica, a referida autora (SAFFIOT, 2005, p. 42), reconhece a violência doméstica como uma consequência deste modelo de subjugação da mulher, pois desta forma, seria, novamente, um modo de dominar, explorar e oprimir o sexo feminino.

Na próxima seção, será apresentado o amálgama entre o citado modelo de desigualdade e a violência no âmbito doméstico. 


\subsection{CORRELAÇÃO ENTRE DESIGUALDADE DE GÊNERO E VIOLÊNCIA DOMÉSTICA}

Após exposto o conceito de patriarcalismo, pode-se dizer que, com um sistema intolerante e prepotente emergindo frente à figura feminina, um movimento que deu voz as mulheres começou a surgir: o feminismo.

Foi no fim do século XVIII, em meio a Revolução Francesa, que Olympe de Gouges apresentou a Assembleia Nacional um documento de extrema importância para a igualdade de gênero: a Declaração dos Direitos da Mulher e da Cidadã4. A proposta de igualdade dos sexos foi rejeitada pelo Parlamento Francês e não chegou à compreensão das raízes da opressão das mulheres (SAFFIOTI, 1976, p. 58).

Entretanto, em 1792, Mary Wollstonecraft protestava por justiça às mulheres e, no meio disso, publicou o livro intitulado como "Reivindicação dos direitos da mulher". A obra foi uma resposta a exclusão das mulheres pela Constituição Francesa (WOLLSTONECRAFT, 2016, p. 8-9), e tinha como intuito denunciar o seguinte:

[...] os prejuízos trazidos pelo enclausuramento feminino na exclusiva vida doméstica e pela proibição do acesso das mulheres a direitos básicos, em especial à educação formal, situação que fazia delas seres dependentes dos homens, submetidas a pais, maridos ou irmãos. (WOLLSTONECRAFT, 2016, p. 8)

Porém, apesar de se iniciar uma luta incessante pela liberdade feminina, ainda estava longe de as mulheres serem ouvidas. Saffioti (1976, p. 57) afirma que "a mulher, [...] assiste a pequena ampliação de seus horizontes sociais: já se distancia do lar para desempenhar uma atividade ocupacional, mas continua impedida de participar da vida pública".

Todavia, esse impedimento de a mulher atuar em outras esferas é explicado por Kate Millett (1969, p. 10), influente feminista na década de 60, a qual afirma que a independência econômica feminina ameaçaria a autoridade masculina e, por consequência, um risco ao modelo de instituição familiar patriarcal.

\footnotetext{
${ }^{4}$ Documento jurídico, contendo 17 (dezessete) artigos, no qual propunha a igualdade das mulheres no âmbito jurídico, político e social.
} 
Hoje, apesar de haver inúmeros discursos protagonizados pelas mulheres, ainda a desigualdade de gênero é notória. Chimamanda Ngozi Adichie (2014, p. 1819) exemplifica o quão díspar é o mundo atual:

\begin{abstract}
Existem mais mulheres do que homens no mundo $-52 \%$ da população mundial é feminina, mas os cargos de poder e prestígio são ocupados pelos homens. A já falecida nigeriana Wangari Maathai, ganhadora do prêmio Nobel da paz, se expressou muito bem e em poucas palavras, quando disse que quanto mais perto do topo chegamos, menos mulheres encontramos.
\end{abstract}

Esta desigualdade fica ainda mais visível quando uma mulher é socializada para demonstrar comportamento dócil, apaziguador, enquanto um homem é estimulado a ter condutas agressivas e que expressam força e coragem (SAFFIOTI, 2004, p. 35).

Além do mais, esta diferença de gênero também se torna evidente a partir do momento em que uma mulher é reificada e, desta forma, torna-se "propriedade" do homem. Com isso, a violência doméstica começa a se implantar dentro das organizações familiares, pois o gênero feminino tem sua autonomia e liberdade tolhida. Assim, a agressão acaba sendo um instrumento de privar a mulher de buscarem a igualdade (ZANATTA; SCHNEIDER, 2017, 78-79).

De acordo com Pierre Bordieu (2012, p. 46), a violência doméstica faz parte de um sistema que favorece aos homens, pois estes são detentores das "armas", como a violência física, psíquica e principalmente simbólica, para se notabilizar na sociedade.

A subjugação feminina inexoravelmente enseja a adoção de políticas afirmativas, o que será contextualizado nas próximas seções.

\title{
2.3 DEFESA DA INTEGRIDADE FÍSICA E PSICOLÓGICA DA VÍTIMA DE VIOLÊNCIA DOMÉSTICA
}

Antes da criação de políticas públicas para amparo de vítimas de violência doméstica, houve diversas convenções que, posteriormente, por pressão destas e juntamente com a recomendação da Organização dos Estados Americanos - OEA, incentivaram o surgimento de uma lei nacional que tivesse o escopo de proteger a mulher agredida em âmbito familiar (FERNANDES, 2012, p. 80). 
Podem ser mencionadas: a Convenção sobre a Eliminação de Todas as Formas de Discriminação contra as Mulheres $^{5}$ e a Convenção Interamericana para Prevenir, Punir e Erradicar a Violência contra a Mulher ${ }^{6}$.

Embora o Brasil tenha aderido às citadas convenções nos anos de 2002 e 1996, respectivamente, não havia nenhuma medida efetiva para proteção às mulheres vítimas de violência doméstica no Brasil (CAMPOS; CORRÊA, 2007, p. 42).

Esta discussão só veio à tona quando Maria da Penha Maia Fernandes sofreu dois atentados contra sua vida, e um deles deixando-a paraplégica. Após uma consequência física e psicológica irreversível, Maria da Penha decidiu denunciar seu agressor:

\begin{abstract}
Acordei de repente com um forte estampido dentro do quarto. Abri os olhos. Não vi ninguém. Tentei mexer-me, mas não consegui. Imediatamente fechei os olhos e um só pensamento me ocorreu: 'Meu Deus, o Marco me matou com um tiro'. Um gosto estranho de metal se fez sentir, forte, na minha boca, enquanto um borbulhamento nas minhas costas me deixou ainda mais assustada. Isso me fez permanecer com os olhos fechados, fingindo me de morta, pois temia que Marco me desse um segundo tiro (FERNANDES, 2012, p. 28).
\end{abstract}

A partir desta denúncia, houve diversas tentativas de punir o agressor, porém, depois de prolatada a sentença, o recurso foi impetrado de imediato e, como já esperado, o julgamento anterior foi anulado (FERNANDES, 2012, p. 78-79).

Por conseguinte, em 2001, foi publicado um relatório pela Comissão Interamericana de Direitos Humanos ${ }^{7}$, que responsabilizou o Brasil por violar os direitos humanos quando o agressor não foi punido e isso tomou proporção internacional. Pode-se dizer que isso serviu de incentivo para debater o tema, pois em 2006 foi criada uma lei com medidas protetivas e educativas destinadas as vítimas de violência doméstica, chamada informalmente de "Lei Maria da Penha" (FERNANDES, 2012, p. 80).

\footnotetext{
${ }^{5}$ Promulga a Convenção sobre a Eliminação de Todas as Formas de Discriminação contra a Mulher, de 1979, e revoga o Decreto o 89.460 , de 20 de março de 1984. Disponível em: <http://www.planalto.gov.br/ccivil_03/decreto/2002/D4377.htm>. (BRASIL, 2002).

${ }^{6}$ Mais conhecida como Convenção de Belém do Pará. Disponível em: <http://www.planalto.gov.br/ccivil_03/decreto/1996/D1973.htm>. (BRASIL, 1996)

${ }^{7}$ Trata-se de uma Comissão, no qual é um órgão principal e autônomo da Organização dos Estados Americanos (OEA) encarregado da promoção e proteção dos direitos humanos no continente americano. Disponível em: <http://www.oas.org/pt/>
} 
A partir disso, Leila Linhares Basterd (2011, p. 16) informa que a supramencionada lei buscou impulso em documentos internacionais que tratavam a violência doméstica como responsabilidade do Estado. Assim, o fito da lei n. 11.340/06 foi a proteção de mulheres vítimas de agressão doméstica, além de reprimir a atuação dos agressores. A referida autora, explica o contexto da Lei Maria da Penha:

\begin{abstract}
A Lei Maria da Penha em suas Disposições Preliminares acompanha a posição das Nações Unidas e de organismos e instituições de direitos humanos que ampliou o conceito de segurança acrescentando-lhe um adjetivo importante - segurança humana, considerada elemento-chave na prevenção de conflitos, na redução da pobreza, na promoção do desenvolvimento. Esses organismos intencionais consideram que a violência é uma questão de segurança muito diferente para mulheres e homens e que o medo da violência é um constrangimento permanente sobre a mobilidade de milhões de mulheres limitando seu acesso aos recursos e às atividades básicas (BASTERD, 2011, p. 17)
\end{abstract}

Desde a vigência da nova lei, foram instituídas medidas protetivas de urgência e outros instrumentos assistenciais visando-a garantir os direitos das mulheres no âmbito das relações domesticas e familiares (BRASIL, 2015, p. 10).

A seguir, será exposta a sistemática de proteção à mulher vítima de violência doméstica, bem como uma análise quantitativa dos índices de ocorrências desta natureza.

\title{
3 O DIREITO FRENTE A PROTEÇÃO DA MULHER E A TUTELA DO ESTADO SOBRE AS VITIMAS DE VIOLÊNCIA DOMÉSTICA
}

Depois de analisados os fatores sócio culturais que ensejaram o disparate de condições nas relações domésticas, necessário entender a sistemática de proteção da mulher vítima de violência doméstica na ordem jurídica nacional. No presente capítulo, indexadores de violência pertinentes ao objeto do trabalho serão analisados e, por meio de uma análise qualitativa, a efetividade da Lei 11.340/2006. 


\subsection{PROTEÇÃO DA MULHER VÍTIMA DE VIOLÊNCIA DOMÉSTICA NA ORDEM JURÍDICA NACIONAL}

De acordo com o Centro Feminista de Estudos e Assessoria - CFEMEA, com a elaboração e promulgação da Lei Maria da Penha, foi determinado ao estado a adesão de políticas públicas para que vítimas de violência doméstica pudessem ter proteção, assistência e a oportunidade de reprimir a agressão e o ofensor. Desta forma, seria possível propiciar mudanças e assim conquistar a igualdade de gênero (CFEMEA, 2009, p. 27).

Com o intuído de proteger os direitos fundamentais à luz do princípio da igualdade, $\mathrm{o}$ artigo $3^{\circ}$ da lei 11.340/06 determinou ao poder público que fosse garantido às mulheres agredidas em âmbito doméstico e familiar a condição de exercer, de forma eficaz, seus direitos, quais sejam "[...] direitos à vida, à segurança, à saúde, à alimentação, à educação, à cultura, à moradia, ao acesso à justiça, ao esporte, ao lazer, ao trabalho, à cidadania, à liberdade, à dignidade, ao respeito e à convivência familiar e comunitária" (BRASIL, 2006).

Ademais, a Lei Maria da Penha visa à proteção feminina e as providências previstas nesta auxiliam a vítima a romper a situação de violência. Com isso, as medidas protetivas de urgência, uma das formas mais eficazes de proteção, correspondem a um mecanismo que objetiva proporcionar a mulher uma vida digna e sem violência, assim como punir o agressor (DIAS, 2019, p. 171).

As medidas protetivas não têm apenas o propósito de aumentar a forma de proteção e prevenção das vítimas de violência doméstica, mas também dar uma autonomia ao magistrado para que possa determinar qual medida aplicar, de acordo com o caso que precisará da atuação judiciária (BIANCHINI, 2016, p. 181).

Conforme o disposto por Alice Bianchini (2016, p. 181), as principais características das medidas protetivas de urgência estão tipificadas do art. 18 ao 24 da lei 11.340/06. São estes: Caráter primordial de urgência, sendo que o juiz deverá decidir sobre o pedido
de medidas protetivas no prazo de 48 horas - art. 18; Podem ser concedidas
pelo juiz, a requerimento do Ministério Público ou a pedido da ofendida - art.
19 , caput; Podem ser decretadas de ofício pelo juiz - art. 20; Não há
necessidade de audiência das partes, nem de manifestação prévia do
Ministério Público, para a concessão da medida - art. 19, $\S 1^{\circ}$; Podem ser 
aplicadas isolada ou cumulativamente - art. 19, § 20; A substituição de uma medida protetiva por outra (mais ou menos drástica) pode se dar a qualquer tempo, desde que garantida a sua eficácia - art. 19, $\S 2^{\circ}$; Dividem-se em duas espécies: (a) As que obrigam o agressor - art. $22 \mathrm{e}$; (b) aquelas dirigidas à proteção da vítima e seus dependentes - arts. 23 e 24 (BRASIL, 2006).

Com isso, estas medidas de proteção não são exclusivas à ofendida, mas também dirigidas ao agressor, pois podem-se aplicadas as medidas protetivas em desfavor do violentador e obrigá-lo a se afastar da vítima, para garantir a segurança desta. A prevenção e repressão às formas de violência doméstica exige da integração dos entes públicos e organizações não governamentais para a manutenção destas políticas públicas (DIAS, 2019, p. 249-250).

\section{2 ÍNDICES DE VIOLÊNCIA DOMÉSTICA NO BRASIL}

Indiscutivelmente, a Lei Maria da Penha é uma grande conquista jurídica para as mulheres, no que diz respeito ao controle de violência doméstica. A Lei apresenta tratamento judiciário diferenciado em relação à proteção da vítima de violência doméstica, bem como em relação ao agressor (BRASIL, 2016, p. 18).

Contudo, é importante frisar que a lei, por si só, não traz mudanças efetivas quanto à realidade social, pois a responsabilidade do legislador é a de meramente garantir a penalização do agressor ao aplicar a Lei 11.340/06 (BRASIL, 2016, p. 18).

À vista disso, conclui-se que, mesmo com um mecanismo rigoroso no combate a violência doméstica, ainda os índices de agressões contra a mulher em esfera familiar são alarmantes. De acordo com o Anuário Brasileiro de Segurança Pública (FÓRUM BRASILEIRO DE SEGURANÇA PÚBLICA, 2019, p. 109), em 2018 houve, no Brasil, 263.067 casos registrados de lesão corporal dolosa decorrente da violência doméstica (Art. $129^{\circ}, \S^{\circ}$ do CP, BRASIL, 1940), número ainda que pode ser aquém da realidade, tendo em vista que muitas das vítimas tem medo de realizar a denúncia.

Também, conforme descrito em pesquisa realizada pelo Instituto de Pesquisa Econômica Aplicada - IPEA, publicado no Atlas da Violência em 2019, "houve um crescimento dos homicídios femininos no Brasil em 2017, com cerca de 13 assassinatos por dia. Ao todo, 4.936 mulheres foram mortas, o maior número registrado desde 2007" (IPEA, 2019, p. 35). 
O estudo ainda preceitua que $28,5 \%$ dos homicídios contra mulheres foram consumados dentro do âmbito residencial. Acredita-se que esses casos são de feminicídios, ou seja, consequência de violência doméstica (IPEA, 2019, p. 35).

Por conseguinte, durante a crise sanitária do país em decorrência da pandemia causada pela Covid-19, houve um aumento significativo nos casos de violência doméstica. Por mais que o isolamento social seja importante para a questão de saúde do País, uma das maiores consequências direta dessa medida, "além do aumento dos casos de violência, tem sido a diminuição das denúncias, uma vez que em função do isolamento muitas mulheres não têm conseguido sair de casa para fazê-la ou têm medo de realizá-la pela aproximação do parceiro" (FÓRUM BRASILEIRO DE SEGURANÇA PÚBLICA, 2020, p. 3).

Neste viés, mesmo com altos índices de violência doméstica, há um agravante que confere ainda mais o aumento destes fatores. Consoante estudo publicado em periódico Texto para Discussão (CERQUEIRA; MOURA; PASINATO, 2019, p. 17), há o dobro de ocorrências de agressões contra as mulheres, quando estas são economicamente ativas.

Essa exposição revela que, mesmo com a instituição de uma lei tão significativa, ainda há um grande número de agressões sendo registradas pelas autoridades pública.

$\mathrm{Na}$ próxima seção, será apresentada uma análise qualitativa dos dados apresentados e se, de fato, somente a imputação da lei 11.340/06 é o suficiente para amparar as vítimas de violência doméstica.

\subsection{PERSPECTIVA QUALITATIVA DOS DADOS APRESENTADOS}

A criação da lei 11.340/2006 trouxe um diferencial no tratamento ao combate à violência doméstica e familiar contra a mulher. Inegável que essa lei resultou em mudanças significativas e proporcionou medidas penais e extrapenais na proteção da vítima de violência doméstica.

Entretanto, mesmo com a instituição da lei supramencionada, o número de vítimas resultantes da violência doméstica é preocupante. Isso corrobora a necessidade da atuação estatal na implementação de outras medidas assecuratórias.

Neste sentido, Jesús-María Silva Sánchez (2013, p. 68) preceitua o seguinte: 
Já que a sociedade não foi capaz de evitar que a vítima sofresse o trauma causado pelo delito, tem, ao menos em princípio, uma dívida perante ela, consistente no castigo do autor. No cumprimento dessa dívida perante ela, além disso, somente as penas de prisão e multa cumprem a desejada função simbólica. A pena - se afirma - significa muito para a vítima.

De mesmo modo, nas palavras de Zaffaroni e Pierangeli (2011, p. 102):

É lógico que a pena, ainda que cumpra em relação aos fatos uma função preventiva especial, sempre cumprirá também uma função simbólica. No entanto, quando só cumpre esta última, será irracional e antijurídica, porque se vale de um homem como instrumento para a sua simbolização, o usa como um meio e não como um fim em si, 'coisifica' um homem, ou, por outras palavras, desconhece-lhe abertamente o caráter de pessoa, com o que viola o princípio fundamental em que se assentam os Direitos Humanos.

À vista disso, uma expansão dos mecanismos de proteção às vítimas de violência doméstica seria a alternativa mais favorável. Portanto, poderia ser utilizados novas formas de custódia, não necessariamente os jurídicos penais, mas maneiras efetivas, sejam elas jurídicos ou não-jurídicos (SÁNCHEZ, 2013, p. 75).

De tal forma, que somente o Direito Penal como única forma de proteção a vítima ou combate ao agressor seria em "boa parte inútil, à medida que transfere ao Direito Penal um fardo que ele não pode carregar" (SÁNCHEZ, 2013, p. 79).

Logo, meios alternativos, como por exemplo, a concessão de benefícios previdenciários são formas que poderão ser utilizadas como sistema de amparo às vítimas de violência doméstica, que será objeto do capítulo a seguir.

\section{BENEFÍCIO PREVIDENCIÁRIO COMO PROTEÇÃO ÀS VíTIMAS DE VIOLÊNCIA DOMÉSTICA}

Neste capítulo, será delineado se é exequível a concessão de benefício previdenciário como uma forma de o Estado amparar mulheres vítimas de violência doméstica. Além disso, também será analisada a percepção do benefício auxíliodoença sob a perspectiva do Recurso Especial No 1.757 .775 - SP, o qual deu provimento para que o Instituto Nacional de Seguro Social - INSS concedesse benefício auxílio-doença à essas vítimas. 


\subsection{AMPARO PELO ESTADO À VÍTIMA DE VIOLÊNCIA DOMÉSTICA POR MEIO DE BENEFÍCIOS PREVIDENCIÁRIOS: UMA ALTERNATIVA VIÁVEL?}

Ante interpretação teleológica da Lei Maria da Penha (BRASIL, 2006) e o art. 226, § $8^{\circ}$ da Constituição Federal (BRASIL, 1988), é dever do Estado assegurar a assistência jurídica "à família na pessoa de cada um dos que a integram, criando mecanismos para coibir a violência no âmbito de suas relações".

Por conseguinte, o art. $9^{\circ}, \S 2^{\circ}$, II, Lei 11.340/06, garante à vítima de violência doméstica a manutenção da relação de trabalho caso, em decorrência dessa condição, precise se afastar da atividade laboral.

Portanto, de mesma forma, deve ser garantido à vítima de violência doméstica o direito de ir e vir em segurança, conforme previsto no art. $5^{\circ}, \mathrm{XV}$ da Constituição Federal (BRASIL, 1988), porém, sem que esta tenha prejudicada sua relação de emprego.

Ademais, está previsto em art. $6^{\circ}$ da Constituição Federal (BRASIL, 1988), que "são direitos sociais a educação, a saúde, o trabalho, a moradia, o lazer, a segurança, a previdência social, a proteção à maternidade e à infância, a assistência aos desamparados [...]" na forma desta legislação.

Logo, consoante caput do art. $5^{\circ}$ da Constituição Federal (BRASIL, 1988), a assistência à mulher em situação de violência doméstica poderá ser prestada conforme os princípios e diretrizes supramencionados, pois são garantias fundamentais a todos os brasileiros e aos estrangeiros residentes no País.

Pois bem, o caput do art. $9^{\circ}$ da Lei Maria da Penha (BRASIL, 2006) prescreve que "A assistência à mulher em situação de violência doméstica e familiar será prestada de forma articulada e conforme os princípios e as diretrizes previstos na Lei Orgânica da Assistência Social [..]". À vista disso, pode-se observar que, em art. $4^{\circ}$ da Lei Orgânica da Assistência Social (BRASIL, 1993) é elencado os seguintes princípios:

Art. $4^{\circ} \mathrm{A}$ assistência social rege-se pelos seguintes princípios:

I - supremacia do atendimento às necessidades sociais sobre as exigências de rentabilidade econômica;

II - universalização dos direitos sociais, a fim de tornar o destinatário da ação assistencial alcançável pelas demais políticas públicas; 
III - respeito à dignidade do cidadão, à sua autonomia e ao seu direito a benefícios e serviços de qualidade, bem como à convivência familiar e comunitária, vedando-se qualquer comprovação vexatória de necessidade; IV - igualdade de direitos no acesso ao atendimento, sem discriminação de qualquer natureza, garantindo-se equivalência às populações urbanas e rurais;

V - divulgação ampla dos benefícios, serviços, programas e projetos assistenciais, bem como dos recursos oferecidos pelo Poder Público e dos critérios para sua concessão (BRASIL, 1993).

Por conseguinte, de acordo com os incisos pautados, em especial o inciso II, são universais os direitos sociais e, por meio das políticas públicas, busca-se alcançar o destinatário da ação assistencial (BRASIL, 1993).

Neste sentido, a Seguridade Social, descrita pelo art. 194 da Constituição Federal (BRASIL, 1988), é constituída a partir de três pedras de toque: a saúde, a previdência e a assistência social. Além disso, o aludido artigo garante, em seu inciso I, a "universalidade da cobertura e do atendimento". Portanto, todos, indistintamente, têm isonomia na proteção social.

Ainda assim, de acordo com Frederico Amado (2013, p.23), a seguridade social, compreende no seguinte:

No Brasil, a seguridade social é um sistema instituído pela Constituição Federal de 1988 para a proteção do povo brasileiro (e estrangeiros em determinadas hipóteses) contra riscos sociais que podem gerar miséria e a intranquilidade social, sendo uma conquista do Estado Social de Direito, que deverá intervir para realizar direitos fundamentais de $2^{\mathrm{a}}$ dimensão. Eventos como o desemprego, a prisão, a velhice, a infância, a doença, a maternidade, a invalidez ou mesmo a morte poderão impedir temporária ou definitivamente que as pessoas laborem para angariar recursos financeiros visando atender às suas necessidades básicas e de seus dependentes, sendo dever do Estado Social de Direito intervir quando se fizer necessário na garantia de direitos sociais.

Isto posto, por mais que todos sejam titulares desse direito, é necessário, conforme art. 194, V da Constituição Federal (BRASIL, 1988), haver "equidade na forma de participação no custeio". Logo, os cidadãos devem contribuir para a seguridade social de acordo com o limite financeiro de cada um, pois assim indiretamente será reduzido as "desigualdades sociais mediante a prudente e adequada repartição dos encargos sociais" (BALERA. 2012, p. 37). 
Assim, o art. 201 da Constituição Federal (BRASIL, 1988) institui o Regime Geral de Previdência Social ${ }^{8}$, o qual elenca os aspectos em que um segurado da Previdência Social obterá o benefício pleiteado:

\footnotetext{
Art. 201. A previdência social será organizada sob a forma do Regime Geral de Previdência Social, de caráter contributivo e de filiação obrigatória, observados critérios que preservem o equilíbrio financeiro e atuarial, e atenderá, na forma da lei, a:

I - cobertura dos eventos de incapacidade temporária ou permanente para o trabalho e idade avançada;

II - proteção à maternidade, especialmente à gestante;

III - proteção ao trabalhador em situação de desemprego involuntário;

IV - salário-família e auxílio-reclusão para os dependentes dos segurados de baixa renda;

V - pensão por morte do segurado, homem ou mulher, ao cônjuge ou companheiro e dependentes, observado o disposto no $\S 2^{\circ}$ (BRASIL, 1988).
}

Diante de números elevados em decorrência da violência doméstica, a mulher vítima desse tipo de agressão é afetada física e psicologicamente, e muitas, por precisarem de medidas protetivas de urgência, precisam se afastar do ambiente laboral. Logo, uma medida eficaz é necessária, pois ao passo que para a segurança da vítima, esta precise se afastar do labor, é primordial demandar ao Poder Público.

\subsection{PERCEPÇÃO DO BENEFÍCIO AUXÍLIO-DOENÇA AS VÍTIMAS DE VIOLÊNCIA DOMÉSTICA A LUZ DO RECURSO ESPECIAL N 1.757 .775 - SP}

A preocupação com a integridade física e psíquica da mulher vítima de violência doméstica foi objeto de discussão no Superior Tribunal de Justiça. Logo, medidas protetivas de urgência foram deferidas para que o agressor da ofendida não se aproximasse dela. Entretanto, ao não se sentir segura a ir trabalhar, a recorrente requereu o afastamento do labor, com fulcro nos termos do art. $9^{\circ}$, $\S 2^{\circ}$, da Lei $n$. 11.340/2006, a manutenção do vínculo empregatício, bem como determinado ao INSS o pagamento do período em que esteve afastada (BRASIL, 2019).

Por conseguinte, após a deliberação do caso em apreço, no Recurso Especial no 1.757.775 - SP (BRASIL, 2019), a Sexta Turma do Supremo Tribunal de Justiça entendeu que a solução mais razoável para este caso e para todas as vítimas

${ }^{8}$ Compilado de regras que determinam os direitos e deveres referente ao Regime Público de Previdência Social no Brasil. 
seguradas que precisam se ausentar do trabalho por segurança seria a imposição, ao INSS, dos efeitos remuneratórios do afastamento do trabalho por meio de concessão de benefício previdenciário auxílio doença. Nestes termos (BRASIL, 2019):

\begin{abstract}
RECURSO ESPECIAL. VIOLÊNCIA DOMÉSTICA E FAMILIAR. MEDIDA PROTETIVA. AFASTAMENTO DO EMPREGO. MANUTENÇÃO DO VÍNCULO TRABALHISTA. COMPETÊNCIA. VARA ESPECIALIZADA. VARA CRIMINAL. NATUREZA JURÍDICA DO AFASTAMENTO. INTERRUPÇÃO DO CONTRATO DE TRABALHO. PAGAMENTO. INTERPRETAÇÃO TELEOLÓGICA. INTERPRETAÇÃO EXTENSIVA. PREVISÃO LEGAL. INEXISTÊNCIA. FALTA JUSTIFICADA. PAGAMENTO DE INDENIZAÇÃO. AUXÍLIO DOENÇA. INSTITUTO NACIONAL DO SEGURO SOCIAL. RECURSO ESPECIAL PROVIDO PARCIALMENTE. (BRASIL. Superior Tribunal de Justiça. Sexta Turma. REsp. 1.757.775 - São Paulo, SP - Rel.: Ministro Rogério Schietti Cruz. Julgado em: 20 ago. 2019) (BRASIL, 2019).
\end{abstract}

Na decisão, foi feito uma interpretação extensiva da Lei Maria da Penha (2006) e, por falta de previsão legal, foi equiparado a ofensa a honra da vítima de violência doméstica com uma moléstia que garante o auxílio-doença (BRASIL, 2019).

Por conseguinte, de acordo com o art. 59 da lei 8.213/91:

Art. 59. O auxílio-doença será devido ao segurado que, havendo cumprido, quando for o caso, o período de carência exigido nesta Lei, ficar incapacitado para o seu trabalho ou para a sua atividade habitual por mais de 15 (quinze) dias consecutivos (BRASIL, 1991).

Conforme Rogerio Schietti Cruz, ao relatar o presente julgado:

[...] ante a omissão legislativa, devemos nos socorrer da aplicação analógica que é um processo de integração do direito em face da existência de lacuna normativa e entender que, como os casos de violência doméstica e familiar acarretam ofensa à integridade física ou psicológica da mulher, estes devem ser equiparados por analogia, aos de enfermidade da segurada, com incidência do auxílio-doença, pois, conforme inteligência do art. 203 da Carta Maior, a assistência social será prestada a quem dela necessitar, independentemente de contribuição à seguridade social (BRASIL, 2019).

Pontuado por Scietti Cruz "A vítima de violência doméstica não pode arcar com danos resultantes da imposição de medida protetiva em seu favor" (BRASIL, 2019), ou seja, a manutenção do vínculo empregatício e a concessão do benefício em questão é a forma de as vítimas de violência doméstica não ficarem desamparadas.

Isto posto, a Sexta Turma do Superior Tribunal de Justiça decidiu ser cabível a concessão do benefício previdenciário auxílio-doença em casos desta magnitude e 
determinou ao empregador o pagamento dos primeiros quinze dias de afastamento e o restante pelo INSS (BRASIL, 2019).

No mesmo sentindo, Dias (2007, p. 97) defende:

\begin{abstract}
A solução mais adequada é a sugerida por Rogério Sanches da Cunha e Ronaldo Batista Pinto: A suspensão do contrato de trabalho, no qual a mulher teria mantido seu vínculo empregatício, porém não recebendo salário do empregador, mas sim do órgão previdenciário, a exemplo do que ocorre na licença-gestante e na ausência do empregado por acidente de trabalho.
\end{abstract}

Por conseguinte, em decisão supramencionada (BRASIL, 2019), foi determinado que o empregador pagará os quinze primeiros dias de afastamento e, após esse período o Instituto Nacional de Seguro Social - INSS concederá o benefício auxílio-doença.

Conforme Scietti Cruz, deve haver aplicação analógica ao caso, pois o entendimento deste é que "[...] os casos de violência doméstica e familiar acarretam ofensa à integridade física ou psicológica da mulher, estes devem ser equiparados por analogia, aos de enfermidade da segurada, com incidência de o auxílio-doença" (BRASIL, 2019).

Fica estabelecido que a segurada deve apresentar "[...] documento de homologação ou determinação judicial de afastamento do trabalho em decorrência de violência doméstica e familiar para comprovar que a ofendida está incapacitada a comparecer ao local de trabalho". (BRASIL, 2019). A partir disso, poderá ser o benefício devidamente concedido no período de afastamento.

Por seu turno, em mesmo recurso, também foi deliberado qual órgão julgador competente para apreciar o caso, pois "na ocasião da análise do requerimento formulado, o Juízo de origem entendeu que não teria competência para decidir, sob o argumento de que se tratava de matéria afeta à Justiça do Trabalho" (BRASIL, 2019).

Pois bem, de acordo com o art. 114, I e IX da Constituição Federal, "compete à Justiça do Trabalho processar e julgar" (BRASIL, 1988):

I - as ações oriundas da relação de trabalho, abrangidos os entes de direito público externo e da administração pública direta e indireta da União, dos Estados, do Distrito Federal e dos Municípios; [...] IX - outras controvérsias decorrentes da relação de trabalho, na forma da lei (BRASIL, 1988). 
Desta forma, está determinado no artigo em apreço que a competência será da Justiça do Trabalho quando houver uma relação de trabalho. Isto é, quando a questão controvérsia cingir-se por questões meramente trabalhistas (BRASIL, 2019).

Neste recurso, de acordo Scietti Cruz (BRASIL, 2019), a demandante afastouse do trabalho por consequência das medidas protetivas de urgência deferidas pelo Juízo Criminal. Sendo assim, não há motivo de recorrer à justiça especializada, pois são circunstâncias alheias ao contrato de trabalho.

Ademais, no art. 14 da Lei 11.340/06 é previsto que a competência da Vara especializada para execução das causas decorrentes de violência doméstica:

Art. 14. Juizados de Violência Doméstica e Familiar contra a Mulher, órgãos da Justiça Ordinária com competência cível e criminal, poderão ser criados pela União, no Distrito Federal e nos Territórios, e pelos Estados, para o processo, o julgamento e a execução das causas decorrentes da prática de violência doméstica e familiar contra a mulher (BRASIL. 2006).

Portanto, se a medida protetiva foi determinada pelo juízo de origem, a competência recai a este, pois o afastamento do local de trabalho foi uma consequência da medida protetiva concedida (BRASIL, 2019).

Diante da situação acima exposta, consequentemente, o custeio ao auxíliodoença pelo Estado poderia causar um déficit considerável no erário. Porém, para que isso não ocorra, é determinado pelo art. 120 da lei 8.213/91 que, nos casos de violência doméstica, o INSS poderá ajuizar ação regressiva contra o agressor:

\footnotetext{
Art. 120. A Previdência Social ajuizará ação regressiva contra os responsáveis nos casos de:

$[\ldots]$

II - violência doméstica e familiar contra a mulher, nos termos da Lei $n^{\circ}$ 11.340, de 7 de agosto de 2006 (BRASIL, 1991).
}

Ou seja, uma ação regressiva é uma medida realista em face do agressor, para que este arque com todas as despesas de suas ações e não recaia a responsabilidade ao Estado deste custeio. Esse aspecto, foi conceituado por Fernando Maciel (2015, p. 23), o seguinte:

O art. 120 da Lei n. 8.213/91 não criou um direito ressarcitório em prol do INSS, ao contrário, instituiu um dever de a Previdência Social buscar o ressarcimento das despesas suportadas em face da conduta culposa de 
terceiros. É o que se extrai do caráter imperativo do verbo contido no referido preceito legal ("a Previdência Social proporá ação regressiva contra os responsáveis").

Sendo o INSS responsável pelas verbas federais previdenciárias, tem legitimidade e interesse para defender o patrimônio público, além de ajuizar ações para reaver todo valor custeado a seus segurados por ações de terceiros.

Por fim, apesar de haver uma lei específica visando a combater a violência doméstica e proteger a mulher vítima dessa forma de agressão, é necessário que existam formas alternativas de proteção. No transcorrer deste artigo, foi demonstrado que é alarmante o quanto a agressão física e psicológica em detrimento da mulher se encontra presente no seio familiar. E, a partir disso, a concessão do benefício auxíliodoença torna-se uma forma optativa de tutelar estas vítimas.

\section{CONSIDERAÇÕES FINAIS}

Apesar de haver inúmeras formas de proteção às vítimas de violência doméstica, ainda as agressões emergem dentro das organizações familiares, sendo hoje um dos maiores problemas a ser combatido pelo judiciário e pelo legislativo.

Todavia, é inegável que as mulheres conquistaram inúmeros direitos com o decorrer do tempo. Desde o momento em que movimentos sociais feministas surgiram e tomaram conta de um corpo social completamente patriarcal, houve uma mudança drástica no rumo da história e, hoje, a visibilidade feminina é muito maior.

Ademais, uma recente conquista das mulheres brasileiras foi o advento da Lei Maria da Penha (Lei n. 11.340/06). Embora somente tenha sido elaborada a partir de um fático episódio, esse caderno normativo buscou assegurar mais liberdade e segurança no momento em que uma vítima de violência doméstica decide denunciar seu agressor.

A lei, além de facilitar a comunicação da violência por parte da vítima, assegura medidas protetivas de urgência para que esta tenha sua integridade preservada. No entanto, ao serem concedidas essas medidas, a vítima, muitas vezes, precisará se afastar de sua rotina habitual e, por consequência, ausentar-se de seu ambiente laboral. 
A partir disso, por meio de analogia a outras leis, é possível tutelar as vítimas de violência doméstica por meio de benefício previdenciário auxílio-doença, pois a ofensa à integridade física ou psicológica da mulher pode ser equiparada à uma enfermidade.

Essa novidade jurídica demonstra um cuidado por parte do legislador em querer combater essa situação que, a tempos, persiste em nossa sociedade. Além disso, o direito de ir e vir da mulher vítima de violência doméstica em segurança é o principal objetivo por parte das políticas públicas implantadas.

Por fim, a desconstrução de toda uma dominação histórica poderá, a partir de leis, instituições e operadores da justiça, causar uma transformação na mentalidade da sociedade quando diz respeito a mulher e de como ela é deve, dentro das organizações familiares e perante a coletividade, ser reconhecida.

\section{REFERÊNCIAS}

ADICHIE, Chimamanda Ngozi. Sejamos todos feministas. São Paulo: Companhia das Letras, 2014.

AMADO, Frederico. Direito previdenciário. 3 ed. Salvador: Juspodvim, 2013.

BALERA, Wagner. Sistema de seguridade social. 6.ed. São Paulo: LTr, 2012.

BASTERD, Leila Linhares. Lei Maria da Penha: uma experiência bem sucedida de advocacy feminista. In: CAMPOS, Carmen Hein de (org.). Lei Maria da Penha: comentada em uma perspectiva jurídico-feminista. Rio de Janeiro: Editora Lumen Juris, 2011. p. 13-37.

BIANCHINI, Alice. Lei Maria da Penha: Lei n. 11.340/2006: aspectos assistenciais, protetivos e criminais da violência de gênero. 3. ed. São Paulo: Saraiva, 2016.

BOURDIEU, Pierre. A dominação masculina. 11. ed. Rio de Janeiro: Bertrand Brasil, 2012.

BRASIL. Constituição (1988). Constituição da República Federativa do Brasil. Brasília, DF: Senado Federal: Centro Gráfico, 1988.

BRASIL. Decreto n. 1.973, de $1^{\circ}$ de agosto de 1996. Promulga a Convenção Interamericana para Prevenir, Punir e Erradicar a Violência contra a Mulher, concluída em Belém do Pará, em 9 de junho de 1994. Disponível em:

http://www.planalto.gov.br/ccivil_03/decreto/1996/D1973.htm. Acesso em: 28 maio 2020 
BRASIL. Decreto n. 4.377, de 13 de setembro de 2002. Promulga a Convenção sobre a Eliminação de Todas as Formas de Discriminação contra a Mulher, de 1979, e revoga o Decreto no 89.460 , de 20 de março de 1984. Disponível em:

http://www.planalto.gov.br/ccivil_03/decreto/2002/D4377.htm. Acesso em: 28 mai. 2020

BRASIL. Decreto-lei $n^{\circ}$ 2.848, de 7 de dezembro de 1940. Código Penal. Disponível em: http://www.planalto.gov.br/ccivil_03/decretolei/del2848compilado.htm. Acesso em: maio 2020.

BRASIL. Lei $n^{0}$ 11.340, de 07 de agosto de 2006. Institui Lei Maria da Penha. Disponível em: http://www.planalto.gov.br/ccivil_03/_ato20042006/2006/lei/l11340.htm. Acesso em: 25 maio 2020.

BRASIL. Lei no 8.213, de 24 de julho de 1991. Institui Lei dos Planos de Benefícios Previdenciários. Disponível em:

http://www.planalto.gov.br/ccivil_03/leis//8213cons.htm. Acesso em: 05 fev. 2020.

BRASIL. Lei $n^{\circ}$ 8.742, de 07 de dezembro de 1993. Institui Lei Orgânica da Assistência Social. Disponível em: http://www.planalto.gov.br/ccivil_03/LEIS/L8742compilado.htm. Acesso em: 05 fev. 2020.

BRASIL. Panorama da violência contra as mulheres no Brasil: indicadores nacionais e estaduais. Brasília: Senado Federal, Observatório da Mulher Contra a Violência, 2016. Disponível em: http://www.senado.gov.br/institucional/datasenado/ omv/indicadores/relatorios/BR-2018.pdf. Acesso em: 15 jun. 2020.

BRASIL. Superior Tribunal de Justiça. Recurso Especial $n^{0} 1.757 .775$

(2018/0193975-8) - São Paulo, SP. Relator: Rogerio Schietti Cruz. 20 ago. 2019. Disponível em: https://canalcienciascriminais.com.br/wpcontent/uploads/2019/10/ATC-stj.pdf. Acesso em: 12 jun. 2020.

BRASIL. Supremo Tribunal Federal. Proteção da mulher: jurisprudência do STF e bibliografia temática. Brasília: Supremo Tribunal Federal, 2019. Disponível em: http://www.stf.jus.br/arquivo/cms/publicacaoPublicacaoTematica/anexo/protecao_da _mulher.pdf. Acesso em: 04 jun. 2020.

CAMPOS, Amini Haddad; CORRÊA, Lindinalva Rodrigues. Direitos humanos das mulheres. Curitiba: Juruá, 2007.

CERQUEIRA, Daniel; MOURA, Rodrigo; PASINATO, Wânia. Participação no mercado de trabalho e violência doméstica contra as mulheres no Brasil. Texto para discussão, n. 2501 Rio de Janeiro: Instituto de Pesquisa Econômica Aplicada, 2019. Disponível em: http://www.ipea.gov.br/portal/images/stories/PDFs/TDs/td_2501.pdf. Acesso em: 06 fev. 2020. 
CFEMEA. Lei Maria da Penha: do papel para a vida: comentários à Lei 11.340/2006 e sua inclusão no ciclo orçamentário. 2.ed. Brasília: CFEMEA, 2009. Disponível em: https://br.boell.org/sites/default/files/leimariadapenhadopapelparaavida_2edicao.pdf. Acesso em: 11 jun. 2020.

DIAS, Maria Berenice. A Lei Maria da Penha na justiça: a efetividade da Lei 11.340/2006 de combate à violência doméstica e familiar contra a mulher. São Paulo: Revista dos Tribunais, 2007.

DIAS, Maria Berenice. Lei Maria da Penha na justiça. Salvador: Editora JusPodivm, 2019.

FERNANDES, Maria da Penha Maia. Sobrevivi: posso contar. Fortaleza: Armazém da Cultura, 2012.

FÓRUM BRASILEIRO DE SEGURANÇA PÚBLICA. Anuário brasileiro de segurança pública. São Paulo: Fórum Brasileiro de Segurança Pública, 2019. Anual. Disponível em: http://www.forumseguranca.org.br/wpcontent/uploads/2019/10/Anuario-2019-FINAL_21.10.19.pdf. Acesso em: 14 jun. 2020.

FÓRUM BRASILEIRO DE SEGURANÇA PÚBLICA. Violência doméstica: durante a pandemia de covid-19. São Paulo: Fórum Brasileiro de Segurança Pública, 2020. Disponível em:http://forumseguranca.org.br/wp-content/uploads/2018/05/violenciadomestica-covid-19-v3.pdf. Acesso em: 17 jun. 2020.

IPEA. Instituto de Pesquisa Econômica Aplicada. Atlas da violência. São Paulo: IPEA, 2019. Disponível em: https://forumseguranca.org.br/wpcontent/uploads/2019/06/Atlas-da-Violencia-2019_05jun_vers\%C3\%A3ocoletiva.pdf. Acesso em: 17 jun. 2020.

MACIEL, Fernando. Ações regressivas acidentárias. 3.ed. rev. ampl. e atual. de acordo com o Novo Código de Processo Civil (Lei n. 13.105/2015). São Paulo: Ltr, 2015. Disponível em: http://www.Itr.com.br/loja/folheie/5328.pdf. Acesso em: 09 mar. 2020.

MILLETT, Kate. Política sexual. Lisboa: Dom Quixote, 1969.

NADER, Maria Beatriz. A condição masculina na sociedade. Dimensões: Revista de História da Ufes, Vitória, n. 14, p. 461-480, 2002.

SAFFIOTI, Heleieth lara Bongiovani. A mulher na sociedade de classe: mito e realidade. Petrópolis: Vozes, 1978.

SAFFIOTI, Heleieth lara Bongiovani. Gênero e patriarcado: a necessidade da violência. In: CASTILLO-MARTÍN, Márcia; OLIVEIRA, Suely de (org.). Marcadas a Ferro: violência contra mulher, uma visão multidisciplinar. Brasília: Secretaria Especial de Políticas Para As Mulheres, 2005, p. 35-76. 
SAFFIOTI, Heleieth lara Bongiovani. Gênero, patriarcado, violência. São Paulo: Fundação Perseu Abramo, 2004.

SÁNCHEZ, Jesús-María Silva. A expansão do direito penal: aspectos da política criminal nas sociedades pós-industriais. São Paulo: Revista dos Tribunais, 2013.

WEBER, Max. Economia e sociedade: fundamentos da sociologia compreensiva. São Paulo: Unb - Universidade de Brasília, 2004.

WOLLSTONECRAFT, Mary. Reivindicação do direito das mulheres. São Paulo: Boitempo, 2016.

ZAFFARONI, Eugenio Raúl; PIERANGELI, José Henrique Pierangeli. Manual de Direito Penal Brasileiro: volume I: parte geral. São Paulo: Revista dos Tribunais, 2011.

ZANATTA, M. C.; SCHNEIDER, V. M. Violência contra as mulheres: a submissão do gênero, do corpo e da alma. In: BAGGENSTOSS, Grazielly Alessandra (org.).

Direito das mulheres. Florianópolis: Lumen Juris Direito, 2017. p. 73-97.

Artigo recebido em: 19/08/2020

Artigo aceito em: 29/10/2020

Artigo publicado em: 10/02/2021 